\title{
Anencephalus - First trimester detection
}

\author{
Aliji Nurije ${ }^{1}$, Aliu Filonid ${ }^{2}$, Livrinova Vesna ${ }^{3}$
}

${ }^{1}$ Gynacology/obstetrics PHI "Niti” - Kumanovo, 1300, North Macedonia

${ }^{2}$ University Clinic for Cardiology - Skopje ,North Macedonia

University Clinic for Gynaecology/Obstetrics, Skopje, North Macedonia

\begin{abstract}
Background: Our goal is to present a case of anencephaly, detected during the $1^{\text {th }}$ week of pregnancy.

Case: The patient is a 38 year old in her $3^{\text {rd }}$ pregnancy,. During the $8^{\text {th }}$ week of pregnancy, ultrasound imaging revealed that the embryo had a "jagged" cranial shape, further observation lead to confirmation of the diagnosis and termination of the pregnancy.

Conclusion: Anencephaly is a major congenital anomaly that can be detected early in the first trimester of pregnancy. A "jagged" cranial shape raises suspicion for the presence of this anomaly.
\end{abstract}

\section{Introduction}

Anencephaly is a malformation which is characterized with the partial absence of the brain, skull and scalp and often is accompanied with other neural tube anomalies. Organogenesis begins in the $3^{\text {rd }}-$ $8^{\text {th }}$ week and continues until birth. The defect in question occurs in the $4^{\text {th }}-6^{\text {th }}$ week of pregnancy when the cephalic end of the neural tube closes. Usually the anomaly is diagnosed in the 2nd trimester of the pregnancy. The struggle for even earlier diagnosing still remains. Anencephaly, a subtype of neural tube defects (NTD) statistically is present in 1:1000 - 1:10.000 livebirths ${ }^{1}$ depending on the prenatal screening of different countries in the world, second only to cardiac anomalies. Although the etiology is still unknown, a daily dose of 0,4mg folic acid, 3 months before conception and in the first trimester of pregnancy, has been shown to greatly reduce the incidence of this anomaly. ${ }^{2}$

\section{Materials}

The patient is a 38 year old, in her $3^{\text {rd }}$ planned pregnancy. Her first pregnancies were at the age of 24 and 28 resulting with normal, onterm deliveries. After these she developed secondary infertility. At age 35 a cervical polyp was removed with the histopathological diagnosis polypus fibroadenomatosus cervicis uteri. She was occasionally treated for STD with ureaplasma urealiticum. Her $3^{\text {rd }}$ pregnancy, at the age of 38 , happened spontaneously. She is without ongoing infections and other health complaints. In this case we used the routine investigative tools: routine laboratory tests and Samsung SonoAce X8 ultrasound with 3DC2-6 abdominal probe.

\section{Methodology}

We are presenting a case of anencephaly diagnosed in the first trimester. First ultrasound results were of an embryo of CRL $6,79 \mathrm{~mm}$ which translates to a $6 \mathrm{~W} 4 \mathrm{D}$ old embryo. Second ultrasound after two weeks with CRL 15,5 mm corresponding to 8W 0D old and positive fetal heart action. The age of the embryo is actually $8 \mathrm{~W} 4 \mathrm{D}$ and CRL should be about $19,4 \mathrm{~mm}$. Measurement errors are inside the margin of 2,1 $\mathrm{mm}$ and even taking this into consideration the CRL is inadequate. Besides this discrepancy, the embryo has an "odd" cranial shape which appears to be "jagged" (photo 1) unlike a normal embryo (photo2 of the same age. Next ultrasound in the 11th week furthermore increases the already set doubts of anencephaly. The patient is sent to a tertiary health institution for consulting. A decision was made for the patient to be evaluated with ultrasound every two weeks and during the 13th week the pregnancy was spontaneously terminated.

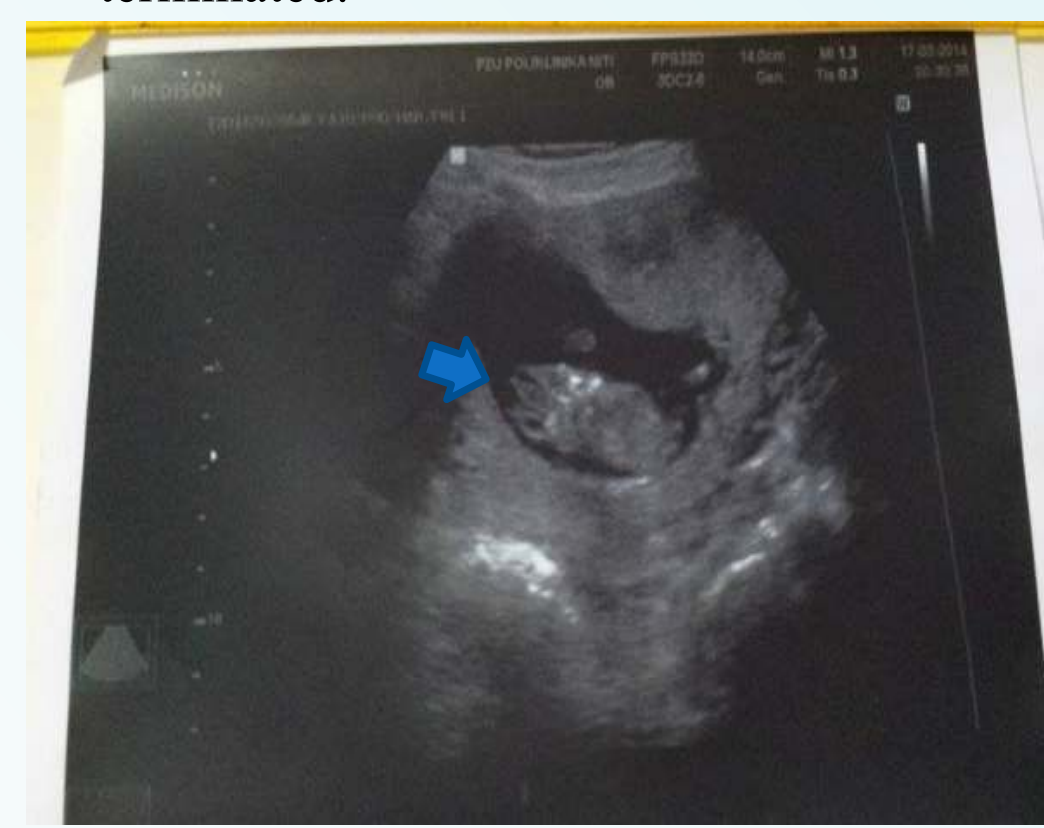

Photo 1

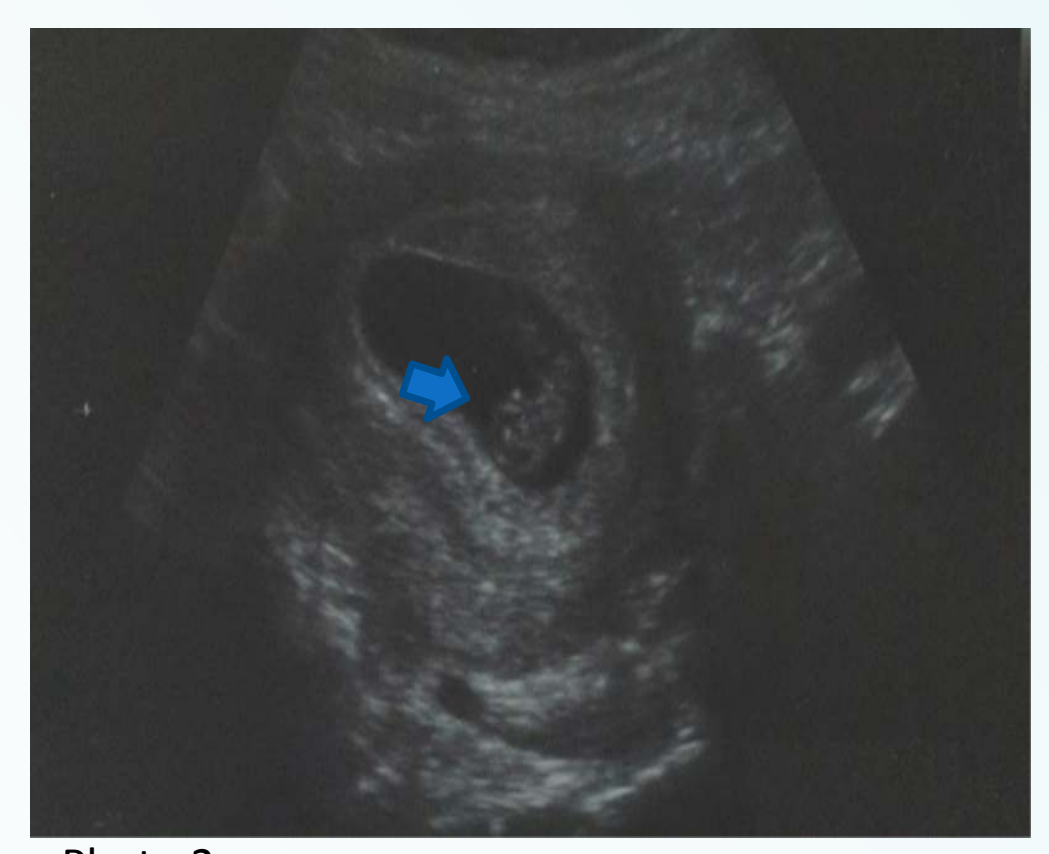

Photo 2

\section{Results}

Suspecting a major anomaly such as anencephaly, the patient was informed and advised to continue further investigations in a tertiary health institution. There, she was evaluated with ultrasound every two weeks after refusing chorion biopsy. The pregnancy terminated spontaneously. The $80 \mathrm{~mm}$ embryo was sent for histopathologic analysis. The diagnosis was confirmed - Anencephalus with rachischisis.

\section{Conclusion}

Anencephaly, as a subtype of NTD, usually is diagnosed during the $2^{\text {nd }}$ trimester of pregnancy. During this period, except using ultrasound, it can also be diagnosed using MSAPF for which the golden period is the 14 $-18^{\text {th }}$ week. Today, with further advancement of ultrasound devices and better sensitivity of tests the period of detection has shifted towards early first trimester. Our case raised high suspicion after the discrepancy in CRL of the first and second ultrasonography. Furthermore, even after changing different positions with the abdominal probe a normal cranium shape was missing and instead an odd, "jagged" formation was seen. Also, the heartbeat doppler signals originated more proximally than in a normal embryo. A vaginal probe investigation was proposed but rejected by the patient. All cases that exhibit one or more of these signs should raise suspicion and be further evaluated. Early termination is in favor of the physical and mental health of the mother.

\section{References}

I. CDC. Recommendations for the use of folic acid to reduce the number of cases of spina bifida and other neural tube defects. MMWR I992;4I(No. RR-I4).

2. Johnson, SP, Sebire, NJ, Snijders, RJM, Tunkel, S,

Nicolaides, $\mathrm{KH}$.

Ultrasound screening for anencephaly at I0-I4 weeks of gestation. Ultrasound Obstet Gynecol. I997;8:14-I6

3. Johnson, S. P., Sebire, N. J., Snijders, R. J., Tunkel, S. and Nicolaides, K. H. (I997),

Ultrasound screening for anencephaly at IO-I4 weeks of gestation. Ultrasound Obstet Gynecol, 9: I4-16

4. Botto LD, Moore CA, Khoury MJ, Erickson JD. Neuraltube defects. N Engl J Med I999; 34I:I509.

5. O'Rahilly R, Muller F. Human embryology and teratology, Wiley-Liss, Inc, New York I992. p.253 